\title{
Course preferences and evaluations of male and female professors by male and female students
}

\author{
LINDA THURSTON BARNETT and GLENN LITTLEPAGE \\ Middle Tennessee State University, Murfreesboro, Tennessee 37132
}

\begin{abstract}
In the first of two studies, college students chose courses in a mock registration. In the second, high school and college students received a biographical and professional summary of a male or female professor and made four judgments of the course and the professor. Neither course choices nor teacher evaluations were influenced by the professor's sex. These results are discussed in terms of previous findings that sex does not influence the evaluations of a product when a clear outside indication of quality is available.
\end{abstract}

Several studies have demonstrated that a person's sex can influence the judged quality of performance. For example, in evaluating professional articles, female subjects gave significantly higher ratings when the author was a male than when the author was a female (Bem \& Bem, 1970, p. 90; Goldberg, 1968). Generalizing from these findings, it was hypothesized that female professors would receive lower student-evaluation scores than would male professors. Furthermore, the classes of female professors would be expected to be less popular and to have smaller enrollments, particularly for elective courses. Such predictions, if substantiated, imply that female professors must exceed their male counterparts in order to receive equal recognition.

Thus, two studies were conducted in order to investigate perceived competence of male and female professors. These studies investigated the following questions: Are there differences in class enrollment preferences related to the professor's sex? Are male and female professors evaluated differentially on studentevaluation forms?

\section{EXPERIMENT 1: REGISTRATION PREFERENCES}

\section{Method}

A total of 47 male and 52 female college students participated in a mock registration. Students were from a regional state university in the southeastern U.S. with a male-to-female student ratio of approximately $1: 1$ and a faculty ratio of approximately $4: 1$. The study was conducted by a female experimenter. Each subject received a trial schedule and a page of information similar to that provided in college catalogues: course titles, course numbers, course descriptions, a faculty list, the advanced degrees obtained, and the dates they were awarded. Sex of the instructor was unobtrusively manipulated by changing the professor's first name. Alternative forms of the information sheet were given to subjects to counterbalance the sex of the professor with other types of information.

Students completed the trial schedules by making four class choices, with each response requiring a choice between two alternatives. Two choices involved choosing between male and female professors. The first required choosing between a male and female professor teaching the same senior-level analytical philosophy course. This choice was between Paul (or Paula) Hunter, a $1963 \mathrm{PhD}$, and Donna (or Donald) Jackson, a 1964 $\mathrm{PhD}$. The second choice involving professors of different sexes required a choice between different junior-level courses, one taught by a male and the other by a female, but with the nature of the course counterbalanced across subjects. This choice involved choosing "introduction to environmental physics" taught by Jan (or Jim) Sheffield, a $1975 \mathrm{PhD}$, or community nutrition taught by Patrick (or Patricia) Thomas, a 1975 EdD. Two filler items required choices between courses taught by recent vs. older graduates, and morning vs. afternoon classes.

Data were tested for overall preferences due to the professor's sex using chi-square tests of a 50-50 split in preference. The dichotomous choices of male and female students resulted in a 2 by 2 table for each question. Chi-square tests of independence were used to determine whether sex of the subject was related to preferences for male or female professors.

\section{Results}

Choices on the two questions involving professor's sex did not reveal statistically significant preferences for male or female professors. For the philosophy course, 26 males and 21 females preferred the female professor, while 21 males and 30 females chose the male professor. Thus, sex of subject did not appear to influence choice of professor $\left[\chi^{2}(1)=1.96\right.$, n.s. $]$, and there was no overall preference for a male or female professor $\left[\chi^{2}(1)=.16\right.$, n.s. $]$.

When asked to choose between a physics and a nutrition course, one taught by a male and the other by a female professor, the sex of the instructor made no difference in the course selection for either course [for physics, $\chi^{2}(1)=2.38$, n.s.; for nutrition, $\chi^{2}(1)=.34$, n.s.; for both courses pooled, $\chi^{2}(1)=1.16$, n.s.]. There were no overall preferences for either of the two courses $\left[\chi^{2}(1)=.26\right.$, n.s. $]$. Furthermore, the sex of the subject did not influence preference for a male or female professor $\left[\chi^{2}(1)=.02\right.$, n.s. $]$. When the male professor taught the physics course and the female professor taught the nutrition course, 19 males and 12 females preferred the male physics professor, while 6 males and 15 females preferred the female nutrition professor. When the physics and nutrition courses were taught by 
a female and male, respectively, 8 males and 17 females preferred the male nutrition professor, and 12 males and 8 females preferred the female physics professor. Thus, there were no general sex preferences, and sex of the subject did not influence the preferred sex of the professor. However, male and female subjects showed differences in the type of course preferred; 14 males and 32 females preferred nutrition and 31 males and 20 females preferred physics $\left[\chi^{2}(1)=8.96, p<.01\right]$.

Analysis of filler items indicated that students preferred morning classes $\left[\chi^{2}(1)=45.5, p<.01\right]$ and that students preferred an urban economics class taught by a professor who recently received his doctorate to a "history of economic thought" course taught by a professor who received a degree in $1942\left[\chi^{2}(1)=49.0\right.$, $\mathrm{p}<.01]$.

\section{EXPERIMENT 2: STUDENT EVALUATION OF HYPOTHETICAL MALE OR FEMALE PROFESSORS}

\section{Method}

Subjects were 110 students from either a high school or college general psychology class: 27 college females, 26 college males, 39 high school senior females, and 18 high school senior males. They rated a male or a female professor on the basis of biographical and professional descriptions.

This study involved students' completing an intuitive evaluation of a male or a female professor based on the following biographical and professional summary: "Dr. James (Jane) Allen is a psychology professor at a local state university. He (She) is a skilled experimenter in his (her) behavioral science field; therefore he (she) is often awarded research grants and has been published in several technical journals. Dr. Allen worked his (her) way through graduate school on assistantships and as a part-time clerk in a department store. He (She) is approximately 30 years old, not married, and lives in a small apartment near campus. His (Her) interests are tennis, backpacking, gourmet cooking, and photography."

The four evaluation items were: (1) I feel that this professor's classes would be too technical or irrelevant. (2) I feel that this teacher would not be tolerant and understanding of my problems as a student. (3) I would like to take a course taught by this professor. (4) I feel that this professor could be a competent teacher. Students responded by indicating agreement or disagreement with each of the four evaluation items on a 6 -point scale, with " 1 " repiesenting agreement, "6" disagreement. Thus, an unweighted-means ANOVA was performed with the following three factors: (1) sex of professor, (2) sex of subject, and (3) high school vs. college student subject.

\section{Results}

Although a difference in the evaluation scores of female and male professors might have been expected, such was not the case (see Table 1). Women did not receive lower evaluation scores on any of the four dependent measures. Similarly, there were no significant effects due to sex of subjects, high school vs. college students, or the interaction of either variable with sex of instructor. The only significant result was a Sex of Subject by High School vs. College Subject interaction for Question 4. For reasons that are not clear, female high school students rated both male and female teachers as less competent than did college females, while high school males rated both male and female teachers as more competent than did college males $[F(1,102)=6.07, p<.05]$.

\section{DISCUSSION}

Results of the mock registration provided no evidence that female professors should have a smaller enrollment in their courses due to either male or female preference for a male teacher. Not surprisingly, however, the data show that students prefer morning classes and that certain courses are more popular among one sex than the other.

In the second study, it was hypothesized that, due to sex prejudices, female professors would be evaluated more negatively, but the results did not confirm this prediction. Thus, the present studies failed to find that female professors are derogated or their courses ignored. A recently completed faculty evaluation at the same university from which college student subjects of this study were recruited (South, Note 1) provides data that support the present findings. The evaluation showed female professors to receive slightly higher ratings than male professors. Although such a naturally occurring difference could be influenced by many factors, it is consistent with the present findings that the performance of female professors is not unfairly derogated.

These findings of no negative bias against female professors were not predicted from the earlier work of Bem and Bem (1970) or Goldberg (1968). Similarly, these results seem to be somewhat inconsistent with Deaux and Taynor's (1973) findings. They studied students' evaluations of the intelligence and competence of highly qualified and unqualified applicants for a study-abroad program. They found that highly competent males were more positively rated than highly competent females and males of low competence were rated lower than lowcompetence females. Since, in the present study, the professors were apparently competent and qualified, Deaux and Taynor's (1973) findings would suggest that male professors should be evaluated more favorably.

One possible explanation for the discrepancy between the present findings and those of earlier studies is a difference in the clarity and degree of outside definition of excellence. In the earlier studies, the subjects had to make their own judgments of quality without help from others, while in the present studies, the person being evaluated was a professor, had a doctorate, and in the second study, had published widely and received several research grants. It is possible that subjects regard these

Table 1

Evaluation of Professors

Male Professor

\begin{tabular}{|c|c|c|c|c|c|c|c|c|}
\hline \multirow[b]{3}{*}{ Item } & \multicolumn{4}{|c|}{ ale } & \\
\hline & \multicolumn{2}{|c|}{ Male Subject } & \multicolumn{2}{|c|}{ Female Subject } & \multicolumn{2}{|c|}{ Male Subject } & \multicolumn{2}{|c|}{ Female Subject } \\
\hline & High School & College & High School & College & High School & College & High School & College \\
\hline Technical/Irrelevant & 4.22 & 4.23 & 4.38 & 4.85 & 4.33 & 4.64 & 4.59 & 4.21 \\
\hline Intolerant & 4.33 & 4.00 & 4.67 & 4.77 & 4.44 & 5.29 & 4.88 & 4.71 \\
\hline Like Course & 2.11 & 2.77 & 2.81 & 2.38 & 2.33 & 2.14 & 2.94 & 1.86 \\
\hline Incompetent & 1.67 & 2.31 & 2.43 & 2.15 & 1.56 & 2.29 & 2.00 & 1.29 \\
\hline
\end{tabular}


accomplishments as clear evidence from reputable sources that the person's performance is of high quality. This interpretation is consistent with a study of judged quality of paintings (Pheterson, Kiesler, \& Goldberg, 1971). Pheterson et al. found that paintings by females were judged to be of lower quality than paintings by men if they were only entered in a contest, but not if the paintings had won an award. These authors concluded that "women who are attempting to accomplish are judged less favorably than men, but that women who have successfully accomplished work are evaluated as favorably as men" (Pheterson et al., 1971, p. 114). Thus the present results are congruent with the Pheterson et al. (1971) conclusions. A college professor with advanced degrees has successfully accomplished work, and thus, there is a clear outside indication that the person is competent. This endorsement may result in less biased student evaluations of female professors. In general, these results might suggest that a female's occupational position and academic degree may serve as an outside stamp of approval that may result in more equitable evaluations.

\section{REFERENCE NOTE}

1. South, D. Student evaluation of faculty Middle Tennessee
State University, Fall 1976. Unpublished manuscript. Middle Tennessee State University, 1977.

\section{REFERENCES}

BEM, S. L., \& BEM, D. J. Case study of a nonconscious ideology: Training the woman to know her place. In D. J. Bem (Ed.), Beliefs, attitudes, and human affairs. Monterey, Calif: Brooks/ Cole, 1970.

Deaux, K., \& Taynor, J. Evaluation of male and female ability. Psychological Reports, 1973, 32, 261-262.

GoldberG, P. A. Are women prejudiced against women? Transaction, April 1968, 28-30.

Pheterson, G. I., Kiesler, S. B., \& Goldberg, P. A. Evaluation of the performance of women as a function of their sex, achievement, and personal history. Journal of Personality and Social Psychology, 1971, 19, 114-118.

(Received for publication October 24, 1978.) 